${ }^{1}$ Faculty of Medicine, Department of Pediatrics,College of Medicine, Gadarif University, Gadarif, Sudan.

${ }^{2}$ Departments of Pediatrics and Medical Education, College of Medicine, University of Bisha, Saudi Arabia.

${ }^{3}$ Unaizah College of Medicine and Medical Sciences, Department of Obstetrics and Gynecology, Qassim University, Unaizah, Kingdom of Saudi Arabia.

${ }^{{ }^{*}}$ King Khalid University, College of Medicine, Department of Obstetrics and Gynecology, Abha, Saudi Arabia.
* Corresponding author: Bahaeldin A. Hassan King Khalid University, College of Medicine, Department of Obstetrics and Gynecology, Abha, Saudi Arabia.

Email: bahasuikt@hotmail.com

Received for publication: August 21, 2020

Accepted: December 21, 2020

\section{Misconceptions and traditional practices toward infant teething symptoms among mothers in eastern Sudan: a cross-sectional study}

\author{
Mohammed Ahmed A. Ahmed ${ }^{1 *}$,Karimeldin M. Salih ${ }^{2}$ \\ (iD, Abdullah Al-Nafeesah ${ }^{3}$, Ishag Adam³ \\ Bahaeldin A. Hassan ${ }^{4, *}$ iD
}

There is no much published data on the mothers' false beliefs about signs and symptoms associated with teething in Sudan. Aim: This cross-sectional hospital-based study was conducted to assess mothers' knowledge about infant teething process and to evaluate mothers' practices used to alleviate teething disturbances in Gadarif city, eastern Sudan. Methods: Questionnaires were used to collect data. Multivariate logistics regression models were performed and adjusted odds ratios (AOR) and 95\% confidence intervals (CI) were calculated. Results/Conclusion: Of a total of 384 participating mothers, 126 (32.8\%) had good knowledge about infant teething. The mothers' knowledge was associated with a higher number of children in the family (adjusted odds ratio $[A O R]=1.14)$ and with having a job $(A O R=2.22)$. Mothers residing in rural areas $(A O R=0.40)$ and mothers with lower than secondary education $(\mathrm{AOR}=0.43$ ) were less likely to have good knowledge about teething. Diarrhea (88.5\%), fever (86.5\%), an urge to bite (76.6\%), and poor appetite (71.9\%) were the signs and symptoms most attributed to teething by mothers. Only the mother's knowledge about teething was associated with reporting fever as a sign. A considerable number (317; 82.6\%) of mothers reported performing "Dokhan" (acacia wood smoke), 313 (81.5\%) preferred to administer paracetamol or other systemic analgesics, 262 (68.2\%) agreed that a child with tooth eruption should be taken to a hospital or health center, and 216 (56.3\%) believed that antibiotics relieved symptoms related to teething.

Keywords: Tooth eruption. Knowledge. Signs and symptoms. Mothers. Child. 


\section{Introduction}

Tooth eruption (teething) is a normal physiological process whereby a tooth moves from within the jaw (intraosseous position) to the oral cavity ${ }^{1}$. Teething usually starts at around six months and continues up to around three years of age ${ }^{2}$.

Symptoms such as fever, diarrhea, dermatitis, constipation, irritability, respiratory diseases, repeated finger sucking, rashes, facial flushing, and poor appetite were believed to be associated with teething ${ }^{3,4}$. Traditionally, "blistering, placing leeches on the gums, and cauterization of the back of the head were the treatment options reported by the parents for teething" ${ }^{\prime \prime}$. Mothers usually use systemic and topical analgesics to relieve teething pain and antibiotics to treat associated symptoms ${ }^{6}$. Moreover, they have their children bite objects to alleviate symptoms ${ }^{7}$. Many medical and non-medical (traditional or other) practices are used as teething treatments without consultation of a dentist or pediatrician.

Mothers' misconceptions about teething might lead to misdiagnosis and mismanagement of potentially serious childhood diseases ${ }^{9}$. Therefore, ideas about teething must be assessed and changed if they are not based on evidence. Although several relevant studies have been conducted in African and other neighboring countries ${ }^{6,10,11}$, little research has been conducted in Sudan and none in eastern Sudan ${ }^{8}$. Therefore, the aim of this study was to assess mothers' knowledge about teething and to evaluate their practices for alleviating teething symptoms in eastern Sudan.

\section{Materials and Methods}

A cross-sectional hospital-based study was conducted between May 1st and May 31st, 2019 in Gadarif Pediatric Teaching Hospital in eastern Sudan. Gadarif is situated at a mean altitude of $496 \mathrm{~m}$ above sea level, has a population of 1,727,401 residents, covers an area of $75,000 \mathrm{~km}^{2}$, and lies between latitudes 14 and 16 north and longitudes 33 and 36 east. It is $400 \mathrm{~km}$ from the capital Khartoum, on the Ethiopian border. Gadarif Pediatric Teaching Hospital is a 170-bed tertiary care facility that serves as a referral center in Gadarif State. It is a public hospital with dental unit which providing a free health services. Between 150 and 200 patients refer to the pediatric outpatient clinic every day. Between 40 and 80 patients are discharged within 24 hours. The pediatric hospital is staffed with 8 consultants, 10 specialists, and 25 medical doctors (registrars and residents).

\section{Inclusion and exclusion criteria}

Mothers with children between six months to three years of age referring to the hospital who agreed to participate were included in the study. Mothers with only one child younger than six months or older that three years of age and mothers with more than one child whose youngest child was over three years old were excluded. Mothers who did not agree to participate and mothers who were mentally unable to communicate were also excluded.

\section{Questionnaire}

A questionnaire composed of four parts was used to collect data. 
The first part regarded sociodemographic information about the mothers and their families.

The second part regarded mothers' knowledge about teething.

The third part concerned symptoms attributed by mothers to teething.

The fourth part concerned treatments used by mothers for teething.

Responses to the second to the fourth sections were structured using "agree," "disagree," and "don't know" options

\section{Sample size}

A sample size of 384 mothers was calculated based on the expected knowledge rate of maximum $50 \%$. The sampling was conducted at a 95\% confidence level with a 5\% margin of error and $80 \%$ power.

\section{Statistics}

IBM SPSS Statistics version 22.0 for Windows was used for the statistical analysis. Absolute numbers and frequencies were used to express mothers' teething-related knowledge, experiences, and practices. Multivariate logistics regression models (using backward likelihood ratios) were performed with mothers' knowledge as a dependent variable (other models were performed for symptoms) and the mothers' age, residence, and education, the children's age and sex, and the number of children in the family as independent variables. Adjusted odds ratios (AOR) and 95\% confidence intervals $(\mathrm{Cl})$ were computed. A two-sided $p$ value less than 0.05 was considered statistically significant.

\section{Results}

\section{General characteristics of the study population}

A total of 384 mothers were enrolled in the study. The ranges and means \pm standard deviations (SD) of the mothers' age, number of children in the family, and age of the youngest child were $16-48$ and $29.2 \pm 6.4$ years, $1-12$ and $3.7 \pm 2.4$, and $6-36$ and $14.7 \pm 8.4$ months, respectively. A total of 294 (76.6\%) mothers resided in rural areas. The education level of 203 (52.9\%) mothers was secondary or higher. Of the 384 children involved in the study, 197 (51.3\%) were male.

\section{Mothers' knowledge about tooth eruption}

Four-fifths $(80.5 \%)$ of the mothers knew that the first primary teeth erupt at 6-7 months, and $89.6 \%$ knew that the lower central incisors are the first to erupt. However, less than half $(167 ; 43.5 \%)$ were aware that delayed eruption could be associated with the presence of a systemic disease. A total of 126 (32.8\%) mothers answered correctly all the questions related to knowledge about teething (Table 1). 
Table 1. Mothers' knowledge about teething

\begin{tabular}{lccc}
\hline & $\begin{array}{c}\text { Yes } \\
\mathbf{n}(\%)\end{array}$ & $\begin{array}{c}\text { No } \\
\mathbf{n}(\%)\end{array}$ & $\begin{array}{c}\text { I don't know } \\
\mathbf{n}(\%)\end{array}$ \\
\hline Teeth start to erupt at 6-7 months. & $309(80.5)$ & $45(11.7)$ & $30(7.8)$ \\
\hline $\begin{array}{l}\text { The lower central incisors are the first } \\
\text { teeth to erupt. }\end{array}$ & $344(89.6)$ & $26(6.8)$ & $14(3.6)$ \\
\hline $\begin{array}{l}\text { Tooth eruption is complete at 2-3 years } \\
\text { of age. }\end{array}$ & $268(69.8)$ & $36(9.4)$ & $80(20.8)$ \\
\hline $\begin{array}{l}\text { Delayed tooth eruption may indicate the } \\
\text { presence of a systemic disease. }\end{array}$ & $167(43.5)$ & $111(28.9)$ & $106(27.6)$ \\
\hline
\end{tabular}

The associations between demographic variables and mothers' knowledge about teething are shown in Table 2. Logistic regression showed that knowledge about teething was associated with a higher number of children in the family ( $A O R=1.14$, $95 \% \mathrm{Cl}=1.4-1.27 ; p=0.007)$ and with having a job $(\mathrm{AOR}=2.22,95 \% \mathrm{Cl}=1.21-4.01$; $p=0.009)$. Mothers residing in rural areas $(A O R=0.40,95 \% \mathrm{Cl}=0.21-0.77 ; p=0.006)$ and mothers with lower than secondary education $(\mathrm{AOR}=0.43,95 \% \mathrm{Cl}=0.25-0.73$; $p=0.002$ ) were less likely to have good knowledge about teething. The mother's age and the age and sex of the youngest child were not significantly related to knowledge about teething (Table 3).

Table 2. Comparing the variables between women with poor and good knowledge

\begin{tabular}{|c|c|c|c|c|}
\hline Variables & $\begin{array}{c}\text { Total } \\
(n=384)\end{array}$ & $\begin{array}{l}\text { Poor knowledge } \\
\qquad(\mathrm{n}=258)\end{array}$ & $\begin{array}{l}\text { Good knowledge } \\
\qquad(\mathrm{n}=126)\end{array}$ & $p$ \\
\hline \multicolumn{5}{|l|}{ Mean (SD) } \\
\hline Mother's age (years) & $29.2(6.4)$ & $29.0(6.5)$ & $29.6(6.1)$ & 0.377 \\
\hline Number of children in the family & $3.7(2.4)$ & $3.6(2.3)$ & $3.9(2.6)$ & 0.284 \\
\hline Age of the youngest child (months) & $14.7(8.8)$ & $14.2(7.9)$ & $15.8(10.0)$ & 0.092 \\
\hline \multicolumn{5}{|l|}{ Number (\%) } \\
\hline \multicolumn{5}{|l|}{ Residence } \\
\hline Urban & $294(76.6)$ & $182(70.5)$ & $112(88.9)$ & \multirow{2}{*}{$<0.001$} \\
\hline Rural & $94(23.4)$ & $76(29.5)$ & $14(11.1)$ & \\
\hline \multicolumn{5}{|l|}{ Mother's education level } \\
\hline Secondary or higher & $203(52.9)$ & $118(45.7)$ & $85(67.5)$ & \multirow{2}{*}{$<0.001$} \\
\hline Below secondary & $181(47.1)$ & $140(54.3)$ & $41(32.5)$ & \\
\hline \multicolumn{5}{|l|}{ Mother's occupation } \\
\hline Housewife & $326(84.9)$ & $232(89.9)$ & $94(74.6)$ & \multirow{2}{*}{$<0.001$} \\
\hline Employee & $58(15.1)$ & $26(10.1)$ & $32(25.4)$ & \\
\hline \multicolumn{5}{|l|}{ Child's sex } \\
\hline Male & $197(51.3)$ & $132(51.2)$ & $65(51.6)$ & \multirow{2}{*}{1.000} \\
\hline Female & $187(48.7)$ & $126(48.8)$ & $61(48.4)$ & \\
\hline
\end{tabular}

SD Standard deviation 
Table 3. multivariate logistic regressions analysis for the factors associated with good knowledge

\begin{tabular}{|c|c|c|c|c|c|c|}
\hline \multirow[b]{2}{*}{ Variables } & \multicolumn{3}{|c|}{ Unadjusted } & \multicolumn{3}{|c|}{ Adjusted } \\
\hline & OR & $\mathrm{Cl}$ & $p$ & OR & $\mathrm{Cl}$ & $p$ \\
\hline Mother's age & 0.95 & $0.90-1.01$ & 0.150 & & & \\
\hline \multicolumn{7}{|l|}{ Residence } \\
\hline Urban & Reference & & & & & \\
\hline Rural & 0.39 & $0.20-0.76$ & 0.005 & 0.40 & $0.21-0.77$ & 0.006 \\
\hline \multicolumn{7}{|l|}{ Mother's education level } \\
\hline Secondary or higher & Reference & & & & & \\
\hline Below secondary & 0.40 & $0.23-0.70$ & 0.001 & 0.43 & $0.25-0.73$ & 0.002 \\
\hline \multicolumn{7}{|l|}{ Mother's occupation } \\
\hline Housewife & Reference & & & & & \\
\hline Employee & 2.39 & $1.30-4.40$ & 0.035 & 2.22 & $1.21-4.01$ & 0.009 \\
\hline Number of children in the family & 1.283 & $1.109-1.48$ & 0.001 & 1.14 & $1.4-1.27$ & 0.007 \\
\hline Age of the youngest child & 1.250 & $0.912-1.70$ & 0.156 & & & \\
\hline \multicolumn{7}{|l|}{ Child's sex } \\
\hline Male & Reference & & & & & \\
\hline Female & 0.97 & $0.61-1.53$ & 0.887 & & & \\
\hline
\end{tabular}

OR Odds ratio, $\mathrm{Cl}$ Confidence interval

\section{Perception of symptoms associated with teething}

Diarrhea (88.5\%), fever (86.5\%), an urge to bite (76.6\%), and poor appetite $(71.9 \%)$ were the most common signs and symptoms attributed to teething by mothers (Table 4). Logistic regression showed that among all the examined factors (mother's knowledge about teething, age, residence, education, and job status, age and sex of the youngest child, and number of children in the family) only the mother's knowledge about teething was associated with reporting fever as a sign. None of the investigated factors were associated with reporting diarrhea as a sign (Table 5).

Table 4. Symptoms attributed to teething by mothers

\begin{tabular}{lccc}
\hline & Yes & No & I don't know \\
$\mathbf{n}(\%)$ & $\mathbf{n}(\%)$ & $6(1.6)$ \\
\hline Fever & $332(86.5)$ & $46(12.0)$ & $2(0.5)$ \\
\hline Diarrhea & $340(88.5)$ & $42(10.9)$ & $12(3.1)$ \\
\hline Vomiting & $260(67.7)$ & $112(29.2)$ & $18(4.7)$ \\
\hline Irritability & $284(74.0)$ & $82(21.4)$ & $14(3.6)$ \\
\hline Poor appetite & $276(71.9)$ & $94(24.5)$ & $14(3.6)$ \\
\hline Excessive salivation & $266(69.3)$ & $104(27.1)$ & $22(5.7)$ \\
\hline Sleep disturbance & $206(53.6)$ & $156(40.6)$ & $41(10.7)$ \\
\hline Ear problems & $110(28.6)$ & $233(60.7)$ & $42(10.9)$ \\
\hline Inflammation of the oral mucosa & $153(39.8)$ & $189(49.2)$ & Continue
\end{tabular}


Continuation

\begin{tabular}{lccc}
\hline Pain & $198(51.6)$ & $165(43.0)$ & $21(5.5)$ \\
\hline Facial flushing & $91(23.7)$ & $232(60.4)$ & $61(15.9)$ \\
\hline Gum irritation & $233(60.7)$ & $118(30.7)$ & $33(8.6)$ \\
\hline Finger sucking & $236(61.5)$ & $127(33.1)$ & $21(5.5)$ \\
\hline Constipation & $85(22.1)$ & $264(68.8)$ & $35(9.1)$ \\
\hline Urge to bite & $294(76.6)$ & $72(18.8)$ & $18(4.7)$ \\
\hline Rhinorrhea & $215(56.0)$ & $139(36.2)$ & $30(7.8)$ \\
\hline Respiratory problems & $177(46.1)$ & $155(40.4)$ & $52(13.5)$ \\
\hline Skin rash & $59(15.4)$ & $260(67.7)$ & $65(16.9)$ \\
\hline Convulsion & $50(13.0)$ & $272(70.8)$ & $62(16.1)$ \\
\hline Increased susceptibility to diseases & $118(30.7)$ & $164(42.7)$ & $102(26.6)$ \\
\hline
\end{tabular}

Table 5. multivariate logistic regressions analysis for the factors associated with fever and diarrhea as signs of infant teething

\begin{tabular}{|c|c|c|c|c|c|c|}
\hline & & Fever & & & Diarrhea & \\
\hline Variables & OR & $\mathrm{Cl}$ & $p$ & OR & $\mathrm{Cl}$ & $p$ \\
\hline Mother's age & 1.02 & $0.96-1.09$ & 0.539 & 1.06 & $0.98-1.14$ & 0.144 \\
\hline \multicolumn{7}{|l|}{ Residence } \\
\hline Urban & Reference & & & & & \\
\hline Rural & 1.98 & $0.87-4.48$ & 0.102 & 0.52 & $0.25-1.12$ & 0.097 \\
\hline \multicolumn{7}{|l|}{ Mother's education level } \\
\hline Secondary or higher & Reference & & & & & \\
\hline Below secondary & 0.93 & $0.47-1.84$ & 0.845 & 1.71 & $0.78-3.70$ & 0.179 \\
\hline \multicolumn{7}{|l|}{ Mother's occupation } \\
\hline Housewife & Reference & & & & & \\
\hline Employee & 1.61 & $0.57-4.50$ & 0.365 & 0.62 & $0.25-1.54$ & 0.310 \\
\hline Number of children in the family & 1.11 & $0.91-1.37$ & 0.227 & 0.96 & $0.77-1.19$ & 0.685 \\
\hline Age of the youngest child & 1.02 & $0.98-1.07$ & 0.235 & 0.99 & $0.96-1.03$ & 0.716 \\
\hline \multicolumn{7}{|l|}{ Child's sex } \\
\hline Male & Reference & & & & & \\
\hline Female & 1.29 & $0.70-2.38$ & 0.407 & 0.95 & $0.50-1.82$ & 0.881 \\
\hline Good knowledge & Reference & & & & & \\
\hline Poor knowledge & 2.50 & $1.13-5.52$ & 0.023 & 1.88 & $0.85-4.18$ & 0.118 \\
\hline
\end{tabular}

OR Odds ratio, $\mathrm{Cl}$ Confidence interval

Table 6 displays the mothers' reported practices for alleviating pain and other teething symptoms. A considerable number of mothers (317; 82.6\%) reported performing "Dokhan" (acacia wood smoke), 313 (81.5\%) preferred to administer paracetamol or other systemic analgesics, 262 (68.2\%) agreed that a child with tooth eruption should be taken to a hospital or health center, and 216 (56.3\%) believed that antibiotics relieved symptoms related to teething. 
Table 6. Treatments provided by mothers for teething

\begin{tabular}{lccc}
\hline & $\begin{array}{c}\text { Yes } \\
n(\%)\end{array}$ & $\begin{array}{c}\text { No } \\
n(\%)\end{array}$ & $\begin{array}{c}\text { Idon't } \\
\text { know } \\
n(\%)\end{array}$ \\
\hline Taking the child to a hospital or health center & $262(68.2)$ & $109(28.4)$ & $13(3.4)$ \\
\hline Performing "Dokhan" (acacia wood smoke) & $317(82.6)$ & $62(16.1)$ & $5(1.3)$ \\
\hline Taking the child to grandmother & $177(46.1)$ & $199(51.8)$ & $8(2.1)$ \\
\hline Taking the child to a more experienced mother in the neighborhood & $113(29.4)$ & $261(68.0)$ & $10(2.6)$ \\
\hline Administering paracetamol or another systemic pain killer & $313(81.5)$ & $66(17.2)$ & $5(1.3)$ \\
\hline Administering extra fluids to prevent dehydration (ORS or other) & $280(72.9)$ & $91(23.7)$ & $13(3.4)$ \\
\hline Administering antibiotics & $216(56.3)$ & $153(39.8)$ & $15(3.9)$ \\
\hline Applying topical analgesia & $99(25.8)$ & $252(65.6)$ & $33(8.6)$ \\
\hline Rubbing the gums with carrots & $169(44.0)$ & $201(52.3)$ & $14(3.6)$ \\
\hline Using sesame oil & $246(64.1)$ & $115(29.9)$ & $23(6.0)$ \\
\hline Giving a pacifier & $95(24.7)$ & $239(62.2)$ & $50(13.0)$ \\
\hline Giving herbs & $144(37.5)$ & $199(51.8)$ & $41(10.7)$ \\
\hline Extracting the teeth & $74(19.3)$ & $283(73.7)$ & $27(7.0)$ \\
\hline Bottle feeding & $98(25.5)$ & $273(71.1)$ & $13(3.4)$ \\
\hline Nothing & $7(1.8)$ & $352(91.7)$ & $25(6.5)$ \\
\hline
\end{tabular}

\section{Discussion}

This study found that $32.8 \%$ of the participating mothers had good knowledge about teething. Knowledge was associated with the number of children in the family, job status, residence, and education level. A study conducted in neighboring Ethiopia reported that $65.4 \%$ of mothers knew that teeth start to erupt at 6-7 months of age, and $74.8 \%$ knew that the lower central incisors are the first to erupt. Their knowledge was associated with their age and place of residence ${ }^{11}$. In a study conducted in Saudi Arabia, over three-quarters (87.5\%) of participants had poor knowledge about teething, and none of the investigated factors were associated with knowledge ${ }^{6}$. Another study similarly found that $60.5 \%$ of parents in Saudi Arabia had poor knowledge about teething and reported that knowledge was significantly associated with a higher number of children in the family ${ }^{9}$. A study conducted in Jordan reported that $65.4 \%$ of mothers knew that tooth eruption normally starts at 6-7 months of age and found that the mothers' knowledge was associated with their age 9 . A considerably higher knowledge rate $(71.4 \%)$ about teething was reported in India ${ }^{12}$.

We observed that diarrhea (88.5\%), fever (86.5\%), and an urge to bite (76.6\%) were the signs and symptoms most commonly attributed to teething by mothers and that citing fever as a symptom was associated with the mother's knowledge. This is in line with a study conducted in Khartoum, Sudan, which reported that fever (86.6\%) and diarrhea (80.3\%) were the symptoms most commonly attributed to teething ${ }^{8}$. However, in that study, the mothers' age and educational status were not associated perceived ${ }^{8}$. In our study, there was no association between the child's sex and systemic signs and symptoms reported by the mother. This is consistent with the findings of Oziegbe et al. ${ }^{10}$, who also found no significant relationship between the child's sex and signs and symptoms noticed by the mother ${ }^{9}$. Also, a study in Ethio- 
pia reported that $91.6 \%$ of the mothers believed that teething was associated with various symptoms, such as diarrhea $(90.7 \%)^{11}$. Owais et al. reported that $75 \%$ of the parents incorrectly associated fever and diarrhea with teething ${ }^{9}$. An urge to bite (93.1\%), fever (87.0\%), and diarrhea (83\%) were the most common signs and symptoms reported by Saudi parents ${ }^{6}$. Contrary to our findings, fever (51.8\%), diarrhea $(12.5 \%)$, and vomiting (2.9\%) were the most commonly reported signs and symptoms by Nigerian mothers ${ }^{10}$.

This and other studies' findings show that although teething does not cause fever, diarrhea, or any respiratory illness, these are common misconceptions related to teething. Unfortunately, such misconceptions may be obstacles to proper diagnosis and effective treatment of many illnesses. A high fever $\left(>39^{\circ} \mathrm{C}\right)$ should not be considered a teething symptom and needs to be investigated. Attention should be paid to detecting or excluding coincidental infections, such as upper respiratory and gastrointestinal infections. A plausible explanation for the presence of coincidental but unrelated systematic diseases during the teething period is a decrease in passive immunity/antibodies ${ }^{13}$.

In our study, $81.5 \%$ of the mothers preferred to administer paracetamol or other systemic analgesics. In contrast, in a study in Ethiopia, only one mother stated that the child should be given paracetamol to relieve symptoms, while $12.1 \%$ reported rubbing children's gums with garlic, and $6.5 \%$ reported rubbing them with herbs to relieve teething pain ${ }^{11}$. In Saudi Arabia, $76.1 \%$ of parents used systemic analgesics, and $65.6 \%$ applied topical analgesics to children's gums ${ }^{9}$.

In our study, $56.3 \%$ of the mothers believed that antibiotics relieved teething-related symptoms. In Saudi Arabia, 45\% of parents believed that antibiotics were indicated for teething ${ }^{6}$. Antibiotic overuse or misuse is a harmful practice for both the individual and the community, as it can lead to bacterial resistance. Unfortunately, in Sudan, antibiotics are sold without restrictions.

This study had certain limitations. As it was a single-center study, its results cannot be generalized to the rest of the population. Moreover, as the data were obtained from mothers' responses regarding teething, they may be subject to recall bias.

In conclusion, this study documents a poor level of knowledge about teething, especially among mothers residing in rural areas and those with a low education level.

\section{Ethics approval}

Ethics approval was obtained from the Ethics Committee of the Faculty of Medicine of Gadarif University (reference number: 2019/012), Sudan. Written informed consent was obtained from each participant.

\section{Competing interests}

The authors declare that they have no competing interests.

\section{Funding}

None received. 


\section{Acknowledgment}

\section{The authors would like to thank all the mothers who participated in the study.}

\section{References}

1. Cunha RF, Pugliesi DM, Garcia LD, Murata SS. Systemic and local teething disturbances: prevalence in a clinic for infants. J Dent Child (Chic). 2004 Jan-Apr;71(1):24-6.

2. Sahin F, Camurdan AD, Camurdan MO, Olmez A, Oznurhan F, Beyazova U. Factors affecting the timing of teething in healthy Turkish infants: a prospective cohort study. Int J Paediatr Dent. 2008 Jul;18(4):262-6. doi: 10.1111/j.1365-263X.2007.00893.X.

3. Massignan C, Cardoso M, Porporatti AL, Aydinoz S, Canto Gde L, Mezzomo LA, Bolan M. Signs and symptoms of primary tooth eruption: a meta-analysis. Pediatrics. 2016 Mar;137(3):e20153501. doi: 10.1542/peds.2015-3501.

4. Tighe M, Roe MF. Does a teething child need serious illness excluding? Arch Dis Child. 2007 Mar;92(3):266-8. doi: 10.1136/adc.2006.110114.

5. Hatibovic-Kofman S, Ari T. Managing discomfort caused by teething. J Can Dent Assoc. 2013;79:d141.

6. Elbur Al, Yousif MA, Albarraq AA, Abdallah MA. Parental knowledge and practices on infant teething, Taif, Saudi Arabia. BMC Res Notes. 2015 Nov;8:699. doi: 10.1186/s13104-015-1690-y.

7. Kumar S, Tadakamadla J, Idris A, Busaily IA, Allbrahim AY. Knowledge of Teething and Prevalence of Teething Myths in Mothers of Saudi Arabia. J Clin Pediatr Dent. 2016;40(1):44-8. doi: 10.17796/10534628-40.1.44.

8. AwadKamil M. Mothers' misconception and traditional practises towards infant teething' symptoms in Khartoum. IOSR J Pharm. 2012 Jan;2(3):448-51. doi: 10.9790/3013-0230448451.

9. Owais Al, Zawaideh F, Al-Batayneh OB. Challenging parents' myths regarding their children's teething. Int J Dent Hyg. 2010 Feb;8(1):28-34. doi: 10.1111/j.1601-5037.2009.00412.x. Erratum in: Int J Dent Hyg. 2010 Nov;8(4):324. Erratum in: Int J Dent Hyg. 2017 Aug;15(3):258.

10. Oziegbe EO, Folayan MO, Adekoya-Sofowora CA, Esan TA, Owotade FJ. Teething problems and parental beliefs in Nigeria. J Contemp Dent Pract. 2009 Jul;10(4):75-82. doi: 10.5005/jcdp-10-4-75.

11. Getaneh A, Derseh F, Abreha M, Yirtaw T. Misconceptions and traditional practices towards infant teething symptoms among mothers in Southwest Ethiopia. BMC Oral Health. 2018 Sep;18(1):159. doi: 10.1186/s12903-018-0619-y.

12. Kakatkar G, Nagarajappa R, Bhat N, Prasad V, Sharda A, Asawa K. Parental beliefs about children's teething in Udaipur, India: a preliminary study. Braz Oral Res. 2012 Mar-Apr;26(2):151-7. doi: 10.1590/ s1806-83242012000200011.

13. Jones M. Teething in children and the alleviation of symptoms. J Fam Health Care. 2002;12(1):12-3. 